\title{
LA LEY APLICABLE AL DIVORCIO Y LA ELEGANCIA DE LA NORMA DE CONFLICTO. APOSTILLAS A LA SENTENCIA DEL TRIBUNAL DE JUSTICIA DE LA UNIÓN EUROPEA DE 16 JULIO 2020"
}

\author{
APPLICABLE LAW TO DIVORCE AND THE ELEGANCE \\ OF THE CONFLICT RULE. COMMENTS \\ ON THE ECJ JUDGEMENT OF 16 JULY 2020
}

\author{
JaVier CARrascosa GonzÁlez \\ Catedrático de Derecho internacional privado \\ Universidad de Murcia \\ ORCID ID: 0000-0002-0347-7985 \\ Recibido: 13.11.2020 / Aceptado: 11.12.2020 \\ DOI: https://doi.org/10.20318/cdt.2021.5986
}

\begin{abstract}
Resumen: Este trabajo realiza una lectura de los principios que rigen la determinación de la Ley aplicable al divorcio en el Reglamento Roma III: certeza legal, seguridad jurídica, costes conflictuales reducidos, lucha contra el Forum Shopping. Tales principios se estudian a través de la sentencia del TJUE de 16 julio 2020, C-249/19, JE vs. KF.

Palabras clave: divorcio, ley aplicable, Forum Shopping, seguridad jurídica, Derecho internacional privado, orden público internacional.
\end{abstract}

Abstract: This work makes a reading of the principles that govern the determination of the Law applicable to divorce in the Rome III Regulation: legal certainty, costs associated with international divorces, fight against Forum Shopping. Such principles are studied in the light of the judgment rendered by the ECJ 16 July 2020, C-249/19, JE vs. KF.

Keywords: divorce, applicable law, Forum Shopping, legal certainty, private international law, public policy.

Sumario: I. Introducción. La Ley aplicable al divorcio internacional. El Reglamento Roma III. II. La sentencia del Tribunal de Justicia de la Unión Europea de 16 julio 2020, C-249/19, JE vs. KF. III. Todos contra el Derecho italiano. 1. La dificultad del divorcio según el Derecho italiano. A) El argumento de la dificultad del divorcio y los arts. 10 y 12 RR-III; B) La respuesta del Tribunal de Justicia de la Unión Europea sobre los arts. 10 y 12 RR-III; C) El art. 10 RR-III. Sus fundamentos metodológicos y valorativos. 2. La inexistencia de un procedimiento de separación judicial en el

\footnotetext{
*Este trabajo se ha realizado en el marco del Proyecto de investigación LOGOS (Fundación BBVA) "Los principios del Derecho romano en el Derecho europeo del siglo XXI" (Proyecto Roma-Europa: IP Javier Carrascosa). https://proyectoromaeuropa.com/), del Grupo de Innovación Docente GID 22 "Ciencia jurídica aplicada y docencia creativa" de la Universidad de Murcia (coordinador: Javier Carrascosa), del Grupo de investigación de la Universidad de Murcia E070-05 "Derecho internacional privado europeo" (IP Javier Carrascosa), de la "Red Europa-España de Derecho internacional privado", (coordinador: Javier Carrascosa). http://www.redespañaeuropa.es/), así como del Grupo Accursio: investigación, docencia y práctica del Derecho internacional privado (www.accursio.com).
} 
Derecho rumano. A) El argumento de la falta de un procedimiento legal de separación judicial en el Derecho rumano. B) La respuesta del Tribunal de Justicia de la Unión Europea. III. Preguntas sin respuesta y respuestas sin preguntas. IV. Las enseñanzas del Tribunal de Justicia de la Unión Europea.

\section{Introducción. La Ley aplicable al divorcio internacional. EI Reglamento Roma III}

1. El Reglamento Roma III constituye la normativa jurídica central aplicable en España para fijar la Ley reguladora de a la separación judicial y del divorcio. Aunque este reglamento es conocido como el "Reglamento Roma III", no es ése su nombre oficial ${ }^{1}$. Es, simplemente, el Reglamento (UE) núm. 1259/2010 del Consejo de 20 diciembre 2010 por el que se establece una cooperación reforzada en el ámbito de la ley aplicable al divorcio y a la separación judicial².

2. El art. 107.2 CC, en su redacción dada por el apartado 28 de la Disposición Final Primera de la Ley 15/2015, de 2 de julio, de la Jurisdicción Voluntaria indica: "La separación y el divorcio legal se regi-

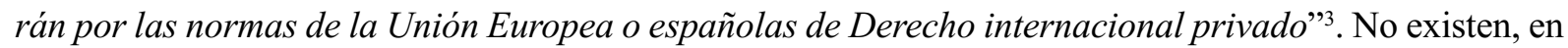
la actualidad, normas españolas de Derecho internacional privado que señalen la Ley aplicable al divorcio y separación judicial. Por ello, esta remisión se debe entender realizada, exclusivamente, en favor del Reglamento Roma III citado, esto es, en favor de las normas europeas de Derecho internacional privado, como bien apunta L.F. CARRILlo Pozo ${ }^{4}$. Así lo como admite la mejor jurisprudencia española, ejemplo de la cual es la SAP Pontevedra 29 julio 2016 [haddana marroquí y divorcio entre cónyuges marroquíes]) 5.

3. El TJUE se había pronunciado dos veces anteriormente sobre la interpretación de este Reglamento, aunque en realidad, se trataba del mismo supuesto de hecho. Así se puede apreciar en el auto TJUE 12 mayo 2016, C-281/15, Soha Sahyouni vs. Raja Mamisch y en la STJUE 20 diciembre 2017, C-372/16, Soha Sahyouni vs. Raja Mamisch .

\footnotetext{
${ }^{1}$ Sobre la elaboración de este reglamento, vid. Comisión de las Comunidades Europeas, "Propuesta de Reglamento del Consejo por el que se modifica el Reglamento (CE) n ${ }^{\circ} 2201 / 2003$ por lo que se refiere a la competencia y se introducen normas relativas a la ley aplicable en materia matrimonial", Documento COM(2006) 399 final, Bruselas, 17 julio 2006; COMISIÓN DE Las Comunidades Europeas, "Libro verde sobre la legislación aplicable y la competencia en asuntos de divorcio", Doc COM (2005) 82 final, Bruselas, 14 marzo 2005; Informe sobre la propuesta de Reglamento del Consejo por el que se modifica el Reglamento (CE) núm. 2201/2003 por lo que se refiere a la competencia y se introducen normas relativas a la ley aplicable en materia matrimonial (COM (2006) 0399 - C6-0305/2006 - 2006/0135 (CNS)), Comisión de Libertades Civiles, Justicia y Asuntos de Interior, elaborado por la Ponente Evelyne Gebhardt, y Ponente de opinión CARLo Casin, Documento de sesión A60361/2008, de 19 septiembre 2008; CoMité ECONÓMICO Y SOCIAL EUROPEO (13 diciembre 2006), Dictamen relativo a la "Propuesta de Reglamento del Consejo por el que se modifica el Reglamento (CE) $n^{\circ}$ 2201/2003 por lo que se refiere a la competencia y se introducen normas relativas a la ley aplicable en materia matrimonial" COM (2006) 399 final, on line version.

${ }^{2}$ Reglamento (UE) núm. 1259/2010 del Consejo de 20 de diciembre de 2010 por el que se establece una cooperación reforzada en el ámbito de la ley aplicable al divorcio y a la separación judicial (DOUE L 343 de 29 diciembre 2010). Participan en este Reglamento Roma III los siguientes Estados miembros de la UE: Bélgica, Bulgaria, Alemania, España, Francia, Italia, Letonia, Luxemburgo, Hungría, Malta, Austria, Portugal, Rumanía y Eslovenia, así como Lituania (desde el 21 noviembre 2012), Grecia (desde el 27 enero 2014), y Estonia (desde el 10 agosto 2016).

${ }^{3}$ BOE núm. de 158 de 3 julio 2015.

${ }^{4}$ L.F. CARrillo Pozo, "Crisis matrimoniales, imperatividad de la norma de conflicto y Derecho extranjero", CDT, 2018, vol. 10, núm. 2, pp. 249-275.

${ }^{5}$ SAP Pontevedra 29 julio 2016 [CENDOJ 36038370012016100396].

${ }^{6}$ Vid. Auto TJUE 12 mayo 2016, C-281/15, Soha Sahyouni vs. Raja Mamisch [ECLI:EU:C:2016:343] y sobre el mismo los comentarios, notas, observaciones y glosas de C. NourISSAT, „Le divorce privé et le droit de l'Union: illustration d'une rencontre avortée“, Procédures, 2016, n. 7, p. 22; T. Helms, „Anwendbarkeit der Rom III-VO auf Privatscheidungen?“, Zeitschrift für das gesamte Familienrecht, 2016 pp. 1134-1135; S.L. GössL, „Anerkennung“ ausländischer Ehescheidungen und der EuGH - Lost in Translation?“, Das Standesamt, 2016, pp. 232-236; A. DutTA, „Für die vom OLG München (StAZ 2015, 373) vorgelegte Frage der Wirksamkeit einer vor einem geistlichen Schariagericht in Syrien durchgeführten (Privat-)Scheidung ist der EuGH nicht zuständig; der Anwendungsbereich der Rom III-VO ist insofern nicht eröffnet", Das Standesamt, 2016, pp. 236-238; V. Michel, „La Cour ne peut que constater l'irrecevabilité manifeste d'une question préjudicielle pourtant intéressante tenant à la reconnaissance d'un divorce prononcé par un tribunal religieux Syrien“, Europe, 2016 Juillet Comm. no 7, pp. 24-25; M. PIKA / M.-PH. Weller, „Privatscheidungen zwischen Europäischem Kollisions- und Zivilprozessrecht“, IPrax, 2017, pp. 65-
} 


\section{La sentencia del Tribunal de Justicia de la Unión Europea de 16 julio 2020, C-249/19, JE vs. KF}

4. La STJUE 16 julio 2020, C-249/19, JE vs. $K F$, constituye la tercera prueba de aplicación del Reglamento Roma III en los estrados del $\mathrm{TJUE}^{7}$. El caso que ha dado lugar a este pronunciamiento puede describirse de la siguiente forma. Dos nacionales rumanos contrajeron matrimonio en Rumanía en el año 2001. En 2016, uno de los cónyuges presentó una demanda de divorcio ante tribunales rumanos. Éstos se declararon competencia con arreglo al foro de la nacionalidad común rumana de ambos cónyuges, pues así figura en el art. 3, apartado 1, letra b), del Reglamento Bruselas II-bis. En la fecha de presentación de la demanda de divorcio, ambos cónyuges tenían su residencia habitual en Italia. Los tribunales rumanos indicaron que la Ley aplicable a este divorcio era la Ley italiana, puesto que los cónyuges no habían elegido ninguna Ley aplicable a su divorcio y éste, en consecuencia, quedaba sujeto a la Ley del país Estado " $a$ ) en que los cónyuges tengan su residencia habitual en el momento de la interposición de la demanda...." (art. 8.1.a) RR-III). Nadie discute, en línea de principio, la aplicación del Derecho italiano al fondo del asunto: el divorcio se rige por la Ley italiana.

5. Ahora bien, ya en un plano de segundo escalón, comienzan las discrepancias jurídicas. En efecto, todo deriva de la distinta idea regulativa que tienen los diferentes Estados sobre el divorcio, institución jurídica polémica donde las haya, indica A.-L. CALVo CARAVACA, incluso todavía hoy después de un recorrido histórico jurídico plagado de sugestivos avatares ${ }^{8}$.

Para el legislador italiano, el divorcio representa el fracaso del matrimonio por antonomasia. El divorcio es un mal remedio para un mal asunto, una desgracia que hay que asumir, pero que no deja de ser un infeliz infortunio, un desastre para los cónyuges, para los hijos, para la familia y para la sociedad.

Frente a ello, para el legislador rumano, el divorcio es, por el contrario, un medio para la realización del libre desarrollo de la personalidad y de la libertad individual. Una salida a una situación personalmente angustiosa, a una familia rota, sin afectos, a una relación personal dañina entre los cónyuges con y que ya no tiene arreglo posible. El divorcio es la libertad, es la posibilidad de comenzar una nueva vida. Es la puerta a un futuro mejor para muchas personas.

Por consiguiente, el legislador italiano trata de dificultar el divorcio. Procura que los cónyuges tarden un cierto tiempo en divorciarse para que puedan meditar bien su decisión y si fuera posible, evitar ese desastre llamado "divorcio". En las antípodas legales se encuentra el legislador rumano, que acoge un di-

72; S.L. Gössel, „Überlegung zum deutschen Scheidungskollisionsrecht nach „Sahyouni“,, Zeitschrift für das Privatrecht der Europäischen Union - GPR, 2018, n 02, pp. 94-99. Vid. STJUE 20 diciembre 2017, C-372/16, Soha Sahyouni vs. Raja Mamisch [ECLI:EU:C:2017:988] y los comentarios debidos a E. ADOBATI, „Il regolamento (UE) n. 1259/2010 non trova applicazione in caso di ,divorzi privati““, Diritto comunitario e degli scambi internazionali, 2017, pp. 627-628; M. NADEMLEINSKY, „Privatscheidung unterfällt nicht Rom III-VO“, Zeitschrift für Ehe- und Familienrecht, 2018, p. 93; N. Fricero / C. Nourissat, „Contentieux Familial - Le divorce privé reste en dehors du champ matériel de la coopération judiciaire civile“, Procédures, 2018 n $^{\circ} 2$, p. 14 ; A. Rigaux, ,Règlement Rome III - Divorce privé prononcé dans un Etat tiers“, Europe, 2018, février nº 2, pp. 71-72; D. COESTERWaltJen, „Dagmar: Die verpasste Chance - Der EuGH und die Privatscheidung“, IPrax, 2018, n. 03, pp. 238-242; S.L. GösSEL, „Überlegung zum deutschen Scheidungskollisionsrecht nach „Sahyouni“",, Zeitschrift für das Privatrecht der Europäischen Union - GPR, 2018, n 02, pp. 94-99; R. Di Meo, „Il diritto europeo e il divorzio privato islamico“, Il Foro italiano, 2018, IV, Col.282-287; E. Viganotti, „Rome III et le divorce sans juge“, Gazette du Palais, 2018 nº 7, pp. 27-29; S. ArNold / M. SCHNETTER, „Privatentscheidungen und die Renaissance der autonomen Kollisionsrechte Europas“, Zeitschrift für europäisches Privatrecht, 2018, pp. 652-666; L. SchlÜRMAnN, „Art. 17 Abs. 2 EGBGB n. F. als überschießende Anwendung der Rom III-VO - das neue Kollisionsrecht für Privatscheidungen nach Sahyouni“, Zeitschrift für das gesamte Familienrecht, 2019, n³, pp. 1035-1040; A. DutTA, „Private divorces outside Rome III and Brussels II bis?: the Sahyouni gap. Case C-372/16, Soha Sahyouni v. Raja Mamich, judgment of the Court (First Chamber) of 20 December 2017, EU:C:2017:988”, Common Market Law Review, 2019, $\mathrm{n}^{\circ}$ 6, pp. 1661-1672. Sobre ambos pronuniciamientos, también, M. ANDRAE, "Antrag auf Scheidung der Ehe bei einem SchariaGericht im Libanon und in Deutschland (OLG Hamm, S. 263)", IPRax, 2018-3, pp. 243-248 y J. AnTomo, "Privatscheidungen und der neue Art. 17 Abs. 2 EGBGB: Rom III-VO à la berlinoise", Das Standesamt, 72, 2, 2019, pp. 33-42.

${ }^{7}$ Esta sentencia ha sido anotada por L. IDOT, "Règlement «Rome III» - Loi applicable au divorce et loi du for", Europe 2020, n 10 Octobre, Comm. 325 y también, mucho más modestamente, por J. CARRASCOSA GonZÁlEz, "Somos rumanos y nos divorciamos en Rumanía pero la ley aplicable a nuestro divorcio es la Ley italiana. ¡Cosas de la vida!”, en http://accursio.com/ blog/?p=1193, 27 septiembre 2020.

${ }^{8}$ A.-L. Calvo Caravaca, "Exequatur de divorcio extranjero en España, nuevas directrices del Tribunal Supremo", $R J$ La Ley, 1983, pp. 251-260. 
vorcio veloz, sin causa, un divorcio que se produce por la pura voluntad de cualquiera de los cónyuges. Para este legislador, el divorcio es un fármaco jurídico eficaz, por lo que cuanto antes se administre, más rápida será la curación. No hay que obligar a los cónyuges a meditar durante ningún tiempo antes del divorcio.

6. Con arreglo al Derecho italiano, en efecto, sólo puede presentarse una demanda de divorcio si un órgano jurisdiccional ha constatado o declarado previamente una separación judicial y si han transcurrido al menos tres años entre la fecha de dicha separación y la fecha de presentación de la demanda de divorcio ante el tribunal. Se trata de un divorcio verdaderamente difícil, complejo y lento. Es lo que los italianos conocen como "il piccolo divorzio". Ello es así porque el legislador italiano, de modo ingenuo, piensa que si la ley dificulta el divorcio entre dos cónyuges que quieren divorciarse, éstos se lo van a pensar mejor y el matrimonio podrá salvarse. Hacer difícil el divorcio para salvar el matrimonio, ésa es su divisa. Así siguen siendo las cosas en el Derecho italiano pese a que, en la actualidad, el plazo de tres años se ha reducido a uno. No es el único legislador que adopta esa visión. También era de esa opinión el legislador español que redactó la Ley 30/1981, de 7 de julio, por la que se modifica la regulación del matrimonio en el Código Civil y se determina el procedimiento a seguir en las causas de nulidad, separación y divorcio, hasta que entró en vigor la Ley 15/2005, de 8 de julio, por la que se modifican el Código Civil y la Ley de Enjuiciamiento Civil en materia de separación y divorcio9. Y también sigue esta línea de política legislativa, por ejemplo, el legislador suizo. En efecto, el art. 114 del Código civil helvético establece que el divorcio instado por un cónyuge sólo procede si han transcurrido al menos dos años desde que ya no viven juntos los cónyuges ${ }^{10}$. Para estos legisladores, en suma, el divorcio es un mal apaño, una medicina dañosa, por lo que establecer por Ley un tiempo para que los cónyuges reflexionen sobre el mismo puede ser útil, precisamente, para evitarlo.

\section{Todos contra el Derecho italiano}

\section{La dificultad del divorcio según el Derecho italiano}

\section{A) El argumento de la dificultad del divorcio y los arts. 10 y 12 RR-III}

7. En el caso examinado, uno de los cónyuges consideraba que, visto que el Derecho italiano no les permitía divorciarse de modo inmediato y rápido, debía aplicarse el art. 10 RR-III. Este precepto afirma lo siguiente: "Cuando la ley aplicable con arreglo a los artículos 5 u 8 no contemple el divorcio o no conceda a uno de los cónyuges, por motivos de sexo, igualdad de acceso al divorcio o a la separación judicial, se aplicará la ley del foro". Es decir, este cónyuge solicitaba que no se aplicase el Derecho italiano (= esto es: divorcio difícil y lento) y que, en su lugar, se diera aplicación al Derecho rumano (= esto es: divorcio sencillo e inmediato). Este cónyuge, pues, da un paso atrás y razona de este modo: visto que el contenido del Derecho italiano no me resulta conveniente, porque me hace esperar varios años antes de obtener el ansiado divorcio, habría que intentar cuestionar la norma de conflicto y evitar que el Derecho italiano rija este

${ }^{9}$ Vid. Ley 15/2005, de 8 de julio, por la que se modifican el Código Civil y la Ley de Enjuiciamiento Civil en materia de separación y divorcio (BOE núm. 163 de 9 julio 2005). Las palabras de la Exposición de Motivos de esta Ley al respecto son elocuentes: “.... esta ley persigue ampliar el ámbito de libertad de los cónyuges en lo relativo al ejercicio de la facultad de solicitar la disolución de la relación matrimonial (....)se estima que el respeto al libre desarrollo de la personalidad, garantizado por el Artículo 10.1 de la Constitución, justifica reconocer mayor trascendencia a la voluntad de la persona cuando ya no desea seguir vinculado con su cónyuge (....) el ejercicio de su derecho a no continuar casado no puede hacerse depender de la demostración de la concurrencia de causa alguna, pues la causa determinante no es más que el fin de esa voluntad expresada en su solicitud, ni, desde luego, de una previa e ineludible situación de separación (...) se pretende reforzar el principio de libertad de los cónyuges en el matrimonio, pues tanto la continuación de su convivencia como su vigencia depende de la voluntad constante de ambos. Así pues, basta con que uno de los esposos no desee la continuación del matrimonio para que pueda demandar el divorcio, sin que el demandado pueda oponerse a la petición por motivos materiales, y sin que el Juez pueda rechazar la petición (....)".

${ }^{10}$ Art. 1141B. Scheidung auf Klage eines Ehegatten / I. Nach Getrenntleben. B. Scheidung auf Klage eines Ehegatten. I. Nach Getrenntleben. Ein Ehegatte kann die Scheidung verlangen, wenn die Ehegatten bei Eintritt der Rechtshängigkeit der Klage oder bei Wechsel zur Scheidung auf Klage mindestens zwei Jahre getrennt gelebt haben". 
divorcio. Es decir: como no me agrada el segundo escalón (= el contenido del Derecho italiano), vuelvo al primer escalón de la norma de conflicto y trato de evitar la aplicación del Derecho italiano.

8. Por si no fuera suficiente, -y es que toda arma es escasa cuando se trata de un litigio de divorcio-, el cónyuge en cuestión indica que, además del art. 10 RR-III, también debería descartarse la aplicación del Derecho italiano porque la aplicación de éste resulta ser manifiestamente incompatible con el orden público del foro (= orden público internacional rumano). También por esa razón, insiste, debería excluirse su aplicación de conformidad con el art. 12 RR-III.

9. En ambos casos, los argumentos esgrimidos cuestionan la Justicia del Derecho sustantivo italiano. El cónyuge considera que la Ley italiana es restrictiva en lo que atañe a los requisitos exigidos para el divorcio. Que no es una Ley justa ni tampoco buena. Por eso, procede, señala, descartar su aplicación y aplicar la Ley rumana al divorcio bien a través del art. 10 ó bien a través del art. 12 RR-III.

\section{B) La respuesta del Tribunal de Justicia de la Unión Europea sobre los arts. 10 y 12 RR-III.}

10. Frente a este ataque en toda regla contra la aplicación del Derecho italiano, el TJUE acude al rescate del entero sistema conflictual del Reglamento Roma III y demuestra, con maestría y lucidez, que no son aplicables a este caso ni el art. 10 RR-III (= precepto previsto para los casos en los que la Ley extranjera no contempla el divorcio) ni el art. 12 RR-III (= excepción de orden público del foro).

11. En primer lugar, apunta el TJUE que el art. 10 RR-III constituye una excepción a los arts. 5 y 8 RR-III, y, como tal, debe ser objeto de una interpretación estricta o restrictiva. Sólo debe activarse este art. 10 RR-III cuando la Ley aplicable "no contemple el divorcio". Y no es el caso.

En efecto, la Ley de 1 diciembre 1970, n. 898, conocida como "Ley Fortuna-Baslini", había introducido el divorcio en el Derecho italiano. Los días 12 y 13 de mayo de 1974 se convocó un referendum para que los ciudadanos italianos se pronunciaran sobre la Ley de modo que los que estuvieran a afavor de su derogación votasen "sí" y los que estuvieran a favor de mantener la ley votaran "no". En este "referéndum abrogativo" venció el "no": la ley se mantuvo y el divorcio también. En suma: en Derecho italiano existe el divorcio.

En consecuencia, no se debe acudir al art. 10 RR-III cada vez que la Ley aplicable al divorcio contemple el divorcio aunque se trate de un divorcio complejo o lento desde el punto de vista del Derecho del Estado miembro cuyos tribunales conocen del asunto. Es decir, si el divorcio según la Lex Causae (= Ley italiana) es más difícil de conseguir que con arreglo a la Lex Fori (= Ley rumana), ello no activa el art. 10 RR-III, que no se refiere a este caso. Tampoco el Cons. 24 RR-III incluye dicho caso en la órbita aplicativa del art. 10 RR-III ${ }^{11}$. En suma, el art. 10 RR-III se aplica solamente a casos en los que la Ley reguladora del divorcio "carece de la figura del divorcio", en sintonía con el art. 13 RR-III, esto es, cuando dicha Ley no contempla el divorcio en forma alguna, como explican U.P. GRUBER y M. GUZMÁN ZAPATER ${ }^{12}$. No es el caso. En conclusión, el art. 10 RR-III es completamente inaplicable a este supuesto.

${ }^{11}$ Cons. (24) Reglamento Roma III: "En algunas situaciones es oportuno, no obstante, que se aplique la ley del órgano jurisdiccional ante el que se ha interpuesto la demanda, por ejemplo cuando la ley aplicable no contemple el divorcio o cuando no conceda a uno de los cónyuges, por razones de sexo, igualdad de acceso al divorcio o a la separación judicial. Estos supuestos deben entenderse, no obstante, sin perjuicio de la cláusula relativa al orden público".

${ }^{12}$ Vid. U.P. Gruber, "Scheidung auf Europäisch - die Rom III-Verordnung", IPRax, 2012-V, pp. 381-391; M. GuZMÁN ZAPATER, "Divorcio, matrimonio y ciertas diferencias nacionales: a propósito de su tratamiento en el artículo 13 del Reglamento Roma III" en C. Esplugues Mota, G. Palao Moreno (Eds), Nuevas Fronteras del Derecho de la Unión Europea. Liber amicorum José Luis Iglesias Buhigues, Valencia, 2012, pp. 521-539. El art. 13 RR-III fue diseñado para abordar la llamada «cuestión maltesa», pues en la fecha de elaboración del precepto, Malta no admitía el divorcio en su Derecho civil. De este modo, el reglamento quiso dejar claro que los tribunales malteses no estaban obligados a dictar una sentencia de divorcio incluso cuando las normas de conflicto del Reglamento ordenase la aplicación de la Ley de un Estado que sí contemplaba el divorcio. Del mismo modo, el precepto también señala que los tribunales de los Estados miembros participantes en el reglamento no estaban obligados a dictar una sentencia de divorcio cuando se trataba de divorciar a cónyuges del mismo sexo si en su Derecho nacional este matrimonio no estaba admitido. 
12. La interpretación restrictiva del art. 10 RR-III sostenida por el TJUE en esta STJUE 16 julio 2020, C-249/19, JE vs. $K F$, es más que correcta. Refuerza la seguridad jurídica y la previsibilidad de soluciones que persigue el Reglamento Roma III. En efecto, salvo casos muy excepcionales y justificadas, previstos por el propio reglamento, la Ley aplicable al divorcio es la señalada por los arts. 5 a 8 RR-III y eso no debe cambiar sea cual sea el tribunal que conozca del asunto, siempre que se trate del tribunal de un Estado miembro. Se impide, así, que un cónyuge acuda ante tribunales de un Estado miembro cuya Ley material establezca condiciones menos restrictivas para el divorcio y solicite la aplicación de dicha Ley mediante una invocación del art. 10 RR-III (= la llamada "cláusula italiana") y/o del art. 12 RR-III (= orden público internacional del foro).

13. En segundo lugar, tampoco es aplicable el art. 12 RR-III que recoge la excepción de orden público internacional. El TJUE no se molesta en modo alguno en rebatir el argumento. Guarda un elocuente silencio al respeto. En realidad, no hay caso. Ningún principio esencial del Derecho rumano se ve perjudicado por la aplicación en Rumanía del Derecho italiano, aunque tal Derecho recoja un divorcio "con período de reflexión".

14. En realidad, explican A.-L. Calvo Caravaca / J. Carrascosa González, la clásica excepción de orden público internacional debe operar, en el sector del divorcio, en un sentido de protección y no de dirección ${ }^{13}$. Como ha escrito P. FranzINA, el art. 12 RR-III da cobijo a un "orden público de protección”, orientado a garantizar los derechos individuales de toda persona. no se trata de imponer uno u otro modelo de familia, ni de matrimonio ni de divorcio, sino de que éste se lleve a término con total respeto a los derechos fundamentales de toda persona ${ }^{14}$.

15. El art. 12 RR-III exige un muy claro "plus de motivación" para descartar la aplicación del Derecho extranjero regulador del divorcio. De ese modo, no basta que la Ley extranjera contenga una regulación "diferente" a la Ley del país cuyos tribunales conocen del asunto en materia de divorcio. Hace notar la profesora P. HAMmJE que la exigencia de que la aplicación del Derecho extranjero resulte "manifiestamente" incompatible con el orden público del foro refuerza la idea de que no basta una mera diferencia en la regulación del divorcio entre tal Derecho y la Ley del foro, para activar este precepto e impedir la aplicación del Derecho extranjero ${ }^{15}$. Puede, por tanto, afirmarse que las normas jurídicas que regulan las causas de divorcio propias del Derecho sustantivo del Estado miembro cuyos tribunales conocen del asunto no constituyen normas materiales imperativas. No se aplican siempre a todo caso de divorcio, sino que, más bien al contrario, son aplicables al divorcio las causas del mismo recogidas en la Ley designada por las normas de conflicto del Reglamento Roma III, en este caso, en el Derecho italiano. El hecho de que la causa de divorcio contemplada por el Derecho extranjero regulador del divorcio, no sea una causa de divorcio prevista en la Lex Fori o viceversa, es irrelevante.

16. El orden público internacional es, -paradojas del Derecho internacional privado-, un concepto "interno" o "nacional", esto es, un concepto cuyo contenido es propio de cada Estado miembro. Cada Estado miembro participante en el Reglamento Roma III dispone de "su orden público internacional" en relación con el divorcio. Algunos ejemplos bastarán. Así, puede subrayarse que deberá intervenir el orden público en casos extremos como el que se plantea cuando, aunque sea legalmente posible el divorcio con arreglo a las normas extranjeras aplicables, resulta, en la práctica, imposible o extraordinariamente

\footnotetext{
${ }^{13}$ A.-L. Calvo Caravaca / J. Carrascosa González (directores), "Crisis matrimoniales", en A.-L. Calvo Caravaca / J. Carrascosa González (directores), Tratado de Derecho internacional privado, primera edición, editorial Tirant Lo Blanch, València, vol. II, 2020, pp. 1741-1756.

${ }^{14}$ P. FranzinA, "The law applicable to divorce and legal separation under regulation (EU) No. 1259/2010 of 20 december 2010", CDT, 2011-II, pp. 85-129; P. FrANZINA, "L'autonomia della volontà nel regolamento sui conflitti di leggi in materia di separazione e divorzio", $R D I, 2011-2$, pp. 488-496.

${ }^{15}$ P. HAMmJe, "Le nouveau règlement (UE) no $1259 / 2010$ du conseil du 20 décembre 2010 mettant en oeuvre une coopération renforcée dans le domaine de la loi applicable au divorce et à la séparation de corps", RCDIP, 2011, pp. 291-338; P. HAMMJE, «La notion de divorce au sens du règlement Rome III - (CJUE 20 déc. 2017, aff. C-372/16), RCDIP, 2018, pp. 899-912.
} 
dificultoso. Es el caso del Derecho de Guinea Ecuatorial, que exige "imprescindiblemente el consentimiento de ambos esposos para la declaración judicial del divorcio del matrimonio" (SAP Barcelona 27 febrero 2014 [divorcio entre cónyuges guineanos] $)^{16}$. También podría recurrirse al orden público internacional cuando la regulación del divorcio resulte discriminatoria para una de las partes por una razón diferente al sexo. En efecto, como expone M.D. Cervilla Garzón, si la Ley aplicable discrimina a un cónyuge por razón de religión, creencia, ideología, etnia, origen social, pertenencia a una organización social concreta, etc., y su aplicación resulta discriminatoria, también de facto, para uno de los cónyuges, el orden público internacional intervendrá ${ }^{17}$. Apunta P. FrANZINA que, por el contrario, cuando la Ley aplicable resulta discriminatoria por razón de sexo en el acceso al divorcio, es aplicable el art. 10 in fine RR-III y no el art. 12 RR-III ${ }^{18}$.

\section{C) El art. 10 RR-III. Sus fundamentos metodológicos y valorativos}

\section{a) Ley aplicable y favor divortii en el art. 10 RR-III}

17. Conviene llamar la atención, brevemente, sobre los fundamentos teóricos del art. 10 RR-III. El precepto recoge la conocida como "cláusula italiana", pues fue tomada por el legislador europeo del art. 31.2 de la legge 218/1995 italiana, precepto que se ocupa de señalar la ley aplicable al divorcio en casos internacionales ${ }^{19}$.

El objetivo de esta cláusula es potenciar el jus connubii del cónyuge (= su derecho a contraer nuevas nupcias, que se vería dañado si no puede disolver el matrimonio anterior), así como la protección de libre desarrollo de la personalidad, esto es, el fomento del individualismo jurídico.

Esta previsión legal favorece la consecución del divorcio (favor divortii), ya que se procede a aplicar la Lex Fori, y la Ley sustantiva de todos los Estados miembros participantes en el Reglamento Roma III admite el divorcio, como ha indicado P. HAMMJE ${ }^{20}$.

Como se ha indicado antes, el art. 10 in primis RR-III sólo es aplicable cuando el divorcio no existe en dicho sistema jurídico. Esta afirmación puede sostenerse en una proyección analógica del Cons. [26] RR-III, que indica que "[l] as referencias del presente Reglamento al hecho de que la ley del Estado miembro participante a cuyos órganos jurisdiccionales se ha recurrido no contempla el divorcio deben interpretarse en el sentido de que la ley de tal Estado miembro carece de la figura del divorcio....". Es decir, esta cláusula operará cuando la Ley extranjera carece de una institución jurídica que permita la disolución legal del matrimonio inter vivos, como el divorcio, tal y como precisa la muy sugestiva sentencia de la Corte di Cassazione italiana de 1 diciembre 2016 [divorcio entre cónyuges albaneses] $]^{21}$.

18. En la actualidad, sólo dos países desconocen en su Derecho sustantivo la figura legal del divorcio como causa de disolución inter vivos del matrimonio: Ciudad del Vaticano y Filipinas. Con arreglo al Derecho filipino, a grandes rasgos, puede afirmarse que sólo se contempla el divorcio para los sujetos

\footnotetext{
${ }^{16}$ SAP Barcelona 27 febrero 2014 [ECLI ES:APB:2014:1184].

${ }^{17}$ M.D. Cervilla Garzón, "La aplicabilidad de las normas del Código de Familia marroquí (la Mudawana) que regulan el divorcio en España: el filtro constitucional”, $C D T$, 2018, pp. 144-163.

${ }^{18}$ P. FrANZINA, "L'autonomia della volontà nel regolamento sui conflitti di leggi in materia di separazione e divorzio", $R D I$, 2011-2, pp. 488-496.

${ }^{19}$ Como explican A.-L. Calvo Caravaca / J. Carrascosa GonzÁlez (directores), "Crisis matrimoniales”, en A.-L. Calvo Caravaca / J. Carrascosa González (directores), Tratado de Derecho internacional privado, primera edición, editorial Tirant Lo Blanch, València, vol. II, 2020, pp. 1741-1756.

${ }^{20} \mathrm{P}$. Hammje, "Le nouveau règlement (UE) n ${ }^{\circ} 1259 / 2010$ du conseil du 20 décembre 2010 mettant en oeuvre une coopération renforcée dans le domaine de la loi applicable au divorce et à la séparation de corps", RCDIP, 2011, pp. 291-338; P. HAMMJE, «La notion de divorce au sens du règlement Rome III - (CJUE 20 déc. 2017, aff. C-372/16), RCDIP, 2018, pp. 899-912; P. HаммJе, «Le divorce par consentement mutuel et le droit international privé», RCDIP, 2017-2, pp. 143-156.

${ }^{21}$ Sentencia de la Corte di Cassazione italiana de 1 diciembre 2016 [divorcio entre cónyuges albaneses], en RDIPP, 2017-4, pp. 1026-1028.
} 
de religión musulmana, pero no para el resto de la población. Así la SAP Barcelona 17 abril 2013 [divorcio entre cónyuges filipinos] se enfrentó aun supuesto de divorcio entre cónyuges filipinos y constató que el Derecho filipino no recogía la posibilidad de divorcio ${ }^{22}$. Por ello el tribunal activó la "cláusula italiana" contemplada en el entonces aplicable art. 107.2 CC y aplicó el Derecho español para divorciar a la pareja. No obstante, según el Derecho de Filipinas, el sujeto filipino casado con extranjero puede divorciarse en el extranjero. La sentencia extranjera será reconocida en Filipinas y el sujeto recuperará, así, su capacidad nupcial en Filipinas. Malta ha sido el Estado antidivorcista que más recientemente ha abrazado el divorcio en su legislación sustantiva (Ley de 25 julio 2011 que introduce el divorcio en Derecho maltés).

19. Tras la admisión del divorcio por la legislación maltesa en 2011, el divorcio se ha hecho "europeo", pues lo admiten todos los Estados miembros de la UE. El art. 10 RR-III persigue, por tanto, en la actualidad, un "objetivo europeo": preservar el derecho al divorcio de todos los ciudadanos que solicitan el divorcio ante tribunales de los Estados miembros participantes, apunta P. FranzINA ${ }^{23}$. Gracias a dicha disposición, nunca será aplicable por tribunales de los Estados miembros participantes en el Reglamento Roma III la Ley de un Estado que no regula ni admite el divorcio como institución jurídica.

20. Es preciso probar que el Derecho extranjero no contempla el divorcio en su legislación. Afirmaciones vagas y generales al respecto no son suficientes, como se aprecia en la SAP Cáceres 23 mayo 2012 [cónyuges marroquíes] ${ }^{24}$. Para acreditar el contenido del Derecho extranjero son aplicables las normas nacionales de cada Estado miembro relativas a la prueba del Derecho extranjero (art. 281.2 LEC y art. 33 LCJIMC en el caso español).

\section{b) Ley que contempla el divorcio pero no la separación judicial y viceversa.}

21. Debe subrayarse que si la Ley extranjera permite la separación judicial pero no el divorcio, el art. 10 in primis RR-III es aplicable y la Lex Fori regulará el caso, siempre que se ejercite una acción de divorcio. En efecto, si se ejercita una acción de separación judicial, ésta se concederá en los términos previstos en la Ley aplicable determinada con arreglo a los arts. 5-8 RR-III.

22. No opera el art. 10 in primis RR-III si la Ley extranjera que rige el divorcio carece de la figura legal de la "separación judicial", pero sí recoge la posibilidad del divorcio vincular o similar. Así se pronuncia, antes del Reglamento Roma III, la SAP Barcelona 12 noviembre 2013 [divorcio entre marroquíes] y también la SAP Málaga 30 enero $2006^{25}$. Con patente error se muestra la SAP Asturias 29 septiembre 2006 [cónyuges rumanos: en Rumanía no existe la separación y el tribunal procedió a la separación de los cónyuges según la Ley material española], así como la SAP Barcelona 3 junio 2008 [divorcio entre cónyuge alemanes] $]^{26}$. Muy correcta, por el contrario, se presenta la sentencia del tribunale di Firenze, Italia, de 15 abril 2009 [divorcio entre sujetos del State de Georgia, US]) ${ }^{27}$.

${ }^{22}$ SAP Barcelona 17 abril 2013 [ECLI:ES:APB:2013:3131]: : “.... siendo una cuestión de orden público, la sala debe revisar la aplicación que el juzgado de primera instancia ha hecho de la legislación española (aunque no cita precepto alguno), sin fundamentarla, pues tanto la demandante como el demandado tiene la nacionalidad filipina y el artículo 107.2 del Código Civil estatal (CC), como norma de conflicto, debe ser aplicado de oficio. Debe confirmarse la aplicación del derecho español, pese a que debería regir el derecho filipino por nacionalidad común, porque el ordenamiento de Filipinas no reconoce el divorcio, que es la excepción prevista en el artículo 107.2.c CC. Según los artículos 81.2 y 86 CC, habiendo trascurrido más de tres meses desde la fecha del matrimonio (21 de mayo de 2009), procede confirmar la declaración de divorcio...". El tribunal emplea de modo impropio la forma verbal "reconoce" (el divorcio) cuando en realidad quiere decir "admite" o "regula" o "contempla".

${ }^{23}$ P. FranZINA, "The law applicable to divorce and legal separation under regulation (EU) No. 1259/2010 of 20 december 2010”, CDT, 2011-II, pp. 85-129.

${ }^{24}$ SAP Cáceres 23 mayo 2012 [CENDOJ 10037370012012100239].

${ }^{25}$ SAP Barcelona 12 noviembre 2013 [CENDOJ 08019370122013100750]; SAP Málaga 30 enero 2006 [CENDOJ 29067370052006100075].

${ }^{26}$ SAP Asturias 29 septiembre 2006 [CENDOJ 33044370042006100344]; SAP Barcelona 3 junio 2008 [CENDOJ 08019370182008100347].

${ }^{27}$ Sent. Trib. Firenze (Italia) 18 mayo 2009 [RDIPP, 2011, p. 145]. 
En estos casos, si se interpone demanda de separación judicial, ésta debe ser desestimada y se indicará a los cónyuges que ejerciten acción de divorcio, como indica la SAP SC Tenerife 28 junio $2004^{28}$.

23. La solución que el art. $10 \mathrm{RR}-\mathrm{III}$ in primis ofrece a este supuesto, -esto es, a la demanda de separación judicial presentada cuando la Ley aplicable sólo prevé el divorcio y no dicha separación-, es diferente a la recogida en el art. 31.2 de la legge 218/1995 italiana. En efecto, con arreglo a esta última disposición, "[l] a separazione personale e lo scioglimento del matrimonio, qualora non siano previsti dalla legge straniera applicabile, sono regolati dalla legge italiana" y de igual manera se pronunciaba el art. 107.2.II.c) CC español. En consecuencia, cuando la Ley extranjera no recoge la figura de la "separación legal", el DIPr. italiano ordena aplicar al juez italiano la Ley sustantiva italiana. Así se parecia en la sentencia del tribunale di Belluno de 30 diciembre 2011 [separación de dos marroquíes con residencia habitual en Italia $]^{29}$.

Por el contrario, con arreglo al art. 10 RR-III, un juez de un Estado miembro participante en el Reglamento que deba aplicar una Ley de un Estado que no contempla la separación legal, como por ejemplo la Ley marroquí, no puede aplicar su Lex Materialis Fori. Deberá desestimar la demanda e indicar a los cónyuges que ejerciten la correspondiente acción de divorcio con arreglo a la Lex Causae.

\section{c) Diferencias entre el art. 10 RR-III y el art. 12 RR-III.}

24. Muy importante es señalar que el mecanismos legal regulado en el art. 10 RR-III no debe ser confundido con el orden público internacional recogido en el art. 12 RR-III, a pesar de ciertas lamentables afirmaciones de algunos analistas del reglamento, que no distinguen entre ambos mecanismos legales.

El art. 10 RR-III recoge una causa de no aplicación de plano de la Ley reguladora del divorcio. Así se desprende, expresamente, del Cons. (24) in fine RR-III. En realidad, el art. 10 RR-III in primis no regula ningún supuesto de orden público internacional "concretizado", sino que opera como una cláusula de "disqualification de la loi normalement compétente", expone B. BouRdelois ${ }^{30}$. A través de esta "primera cláusula de rechazo de plano" de la Ley extranjera, basta comprobar el tenor literal de las normas jurídicas del Derecho extranjero, para descartar la aplicación del mismo en un Estado miembro. Como ha indicado J. CARrascosa GonzÁlez, no es preciso acreditar que, en el caso concreto, la Ley extranjera produce un perjuicio para la estructura jurídica fundamental de la sociedad del Estado miembro participante cuyos tribunales conocen del asunto que es lo que procede llevar a cabo cuando interviene el orden público internacional contemplado en el art. 12 RR-III ${ }^{31}$. Las diferencias de método entre el orden público internacional y la cláusula de rechazo de la Ley extranjera que no contempla el divorcio son abismales.

\section{La inexistencia de un procedimiento de separación judicial en el Derecho rumano.}

\section{A) El argumento de la falta de un procedimiento legal de separación judicial en el Derecho rumano}

25. En el supuesto de hecho de la STJUE 16 julio 2020, C-249/19, JE vs. $K F$, no es sólo uno de los cónyuges el que quiere evitar la aplicación del Derecho italiano. También el tribunal rumano competente para pronunciarse sobre el divorcio se opone a la aplicación del Derecho italiano. Su argumento, eso sí, es ahora completamente distinto. Sotto voce, dicho tribunal hace notar que no le es de su agrado

\footnotetext{
${ }^{28}$ SAP SC Tenerife 28 junio 2004 [CENDOJ 38038370042004100255$]$.

${ }^{29}$ Sentencia del tribunale di Belluno (Italia) de 30 diciembre 2011 [RDIPP, 2012, p. 452].

${ }^{30}$ B. Bourdelois, "Nota a Sent. Cour Cass. Francia 14 febrero 2007 [matrimonio poligámico en Francia]", JDI Clunet, 2007, pp. 934-943.

${ }^{31}$ J. Carrascosa GonzÁlez, "Esclusione dell'applicazione della legge regolatrice del divorzio e regolamento Roma III", Studi sull'integrazione europea, 2017, núm. 2, pp. 267-288.
} 
el Derecho italiano porque dificulta el divorcio al hacerlo lento y complejo. Y entonces, a diferencia del cónyuge demandante, -que, como se ha visto, sigue una estrategia dirigida a alterar el normal funcionamiento de la norma de conflicto-, señala el tribunal rumano que no puede pronunciar el divorcio porque el Derecho italiano, -aplicable al fondo del asunto-, exige, para pronunciar el divorcio que: (i) de manera previa un tribunal haya "constatado o declarado previamente una separación judicial"; y (ii) que hayan transcurrido al menos tres años entre la fecha de dicha separación y la fecha de presentación de la demanda de divorcio ante el tribunal.

26. Pues bien, como resulta que no se ha dictado ninguna sentencia de separación y que, además, "el Derecho rumano no contempla ningún procedimiento de separación judicial", los tribunales rumanos no pueden pronunciar el divorcio, sostiene el tribunal rumano. Toda demanda dirigida a obtener la separación judicial ante los tribunales rumanos debe declararse inadmisible y sin separación judicial no hay divorcio, porque el Derecho italiano exige, para dictar el divorcio, que previamente se obtenga la separación judicial. Es decir, la ecuación, muy sencilla, que enuncia el tribunal rumano, es ésta: la falta de procedimiento de separación judicial en Derecho rumano impide obtener la sentencia de separación judicial ante jueces rumanos y como el Derecho italiano existe que se haya dictado dicha sentencia de separación judicial, -y que, además, hayan transcurrido después al menos tres años-, entonces el tribunal rumano no puede declarar el divorcio. La tormenta perfecta para no aplicar el Derecho italiano al divorcio entre los dos cónyuges rumanos.

27. Para poner la guinda al pastel y que sepa mejor, esto es, para no dejar a los cónyuges sin una posibilidad de divorciarse, el tribunal rumano experimenta un fuerte ataque de creatividad e indica a los cónyuges que acudan a los tribunales italianos para obtener la sentencia de separación judicial.

\section{B) La respuesta del Tribunal de Justicia de la Unión Europea ante la falta de un procedimiento de separación judicial en las leyes procesales rumanas}

28. Señala el TJUE que, aunque el Derecho rumano no contempla la separación judicial en sus leyes sustantivas y procesales, los cónyuges pueden obtener un pronunciamiento de "separación judicial" ante tribunales rumanos, visto que, con arreglo al Derecho italiano, necesitan dicha sentencia de separación judicial como paso previo al divorcio. Debe recordarse que los tribunales rumanos son internacionalmente competentes para pronunciarse sobre dicha separación judicial ex art. 3.1.b) RB II-bis (= nacionalidad común de los cónyuges en el momento de presentación de la demanda).

29. En efecto, el TJUE subraya que la inexistencia de un procedimiento de separación judicial en las leyes procesales rumanas es un hecho que no puede impedir la aplicación de las normas de conflicto europeas ni tampoco la aplicación del Derecho italiano que sí contempla la separación judicial. Dice la STJUE 16 julio 2020, C-249/19, JE vs. KF, FD 42: “..... aunque, contrariamente al Derecho italiano, el Derecho rumano no contemple disposiciones procesales relativas a la separación judicial, los tribunales rumanos competentes están obligados a pronunciarse sobre dicha demanda".

30. Lo anterior significa (i) que los cónyuges deben obtener una sentencia de separación judicial, -pues así lo exige el Derecho italiano, que regula el fondo del divorcio-; (ii) que los tribunales rumanos son competentes al efecto $e x$ art. 3.1.b) RB II-bis; (iii) que existe acción para alcanzar la separación judicial, -pues el Derecho italiano, aplicable al fondo de la separación judicial (art. 8.1 RR-III) regula y admite la separación judicial-, y (iv) que los tribunales rumanos están obligados por el art. 8.1 RR-III y por el Derecho italiano designado por dicho precepto, a pronunciarse sobre la separación judicial.

31. El hecho de que el Derecho rumano (= Lex Fori Processus) carezca de "normas de procedimiento en materia de separación judicial", es totalmente irrelevante. Los cónyuges disponen de acción 
para solicitar el divorcio y también la separación judicial, pues la acción depende de la Lex Causae, -Derecho italiano-, no de la normativa procesal del Estado cuyos tribunales conocen del asunto -Derecho rumano-. Confundir la falta de procedimiento con la falta de acción, como ha sido escrito por algún comentarista, constituye un error infantil, lamentable consecuencia de la falta de estudio. Hay acción, naturalmente que sí. Pero no hay procedimiento, no existe un cauce procedimental diseñado por el legislador rumano. En realidad, este fenómeno es frecuente en caso de Derecho internacional privado. Así por ejemplo, puede existir acción para solicitar, ante tribunales españoles, la extinción de una kafala musulmana regida por el Derecho marroquí. Hay acción para reclamar los daños producidos por una extralimitación del trustee en el ejercicio de sus funciones, por ejemplo porque ha confundido los bienes en trust con los suyos propios o los ha enajenado a un tercero. En ambos casos, el Derecho procesal español carece de un procedimiento para canalizar estas dos acciones. Pero, sin duda ninguna, existe acción.

32. Pues bien, el TJUE afirma que el Derecho procesal está al servicio del Derecho conflictual. Las cuestiones procesales, las cuestiones procedimentales, no pueden impedir que se aplique una norma europea de conflicto de leyes. No pueden perjudicar el efecto útil de tal norma de conflicto europea. Las normas procesales son ancilares a las normas de conflicto. Están a su servicio. Por tanto, aunque el Derecho rumano carece de normas de procedimiento para la separación judicial, el tribunal rumano está obligado a pronunciarse sobre dicha separación judicial. Le obliga a ello la norma de conflicto europea (art. 8.1 RR-III) y el Derecho italiano designado por la misma. Y si el tribunal rumano no dispone de un procedimiento de separación judicial en las normas procesales rumanas, entonces sí es el momento de emplear su creatividad judicial y de comprobar que la separación judicial de los cónyuges es, con arreglo al Derecho italiano, posible. Debe hacerlo constar así en el marco del procedimiento de divorcio del que conoce, por ejemplo, a través de un incidente procesal o cauce similar regulado en su Derecho procesal. Con otras palabras: el tribunal rumano, competente para pronunciarse sobre el divorcio, debe acreditar que la separación judicial de los cónyuges es posible y ello aunque el Derecho rumano no disponga de normas de procedimiento relativas a la separación judicial. El juez rumano comprobará que se verifican los requisitos legales de la separación judicial con arreglo al Derecho italiano y lo hará dentro del procedimiento de divorcio, en el seno de la tramitación de dicho procedimiento y como paso previo para pronunciar el divorcio. Las cuestiones de procedimiento no pueden ni deben interponerse en la aplicación de las normas de conflicto del Reglamento Roma III.

\section{Preguntas sin respuesta y respuestas sin preguntas}

33. Esta STJUE 16 julio 2020, C-249/19, JE vs. KF deja sin responder algunas preguntas que surgen en la mente del jurista de Derecho internacional privado. No sucede eso por desidia del tribunal, sólo faltaría. Sucede porque nadie formuló tales preguntas al tribunal. Sin embargo, en esta sentencia, el TJUE marca con puño de hierro y guante de seda el camino a seguir: son respuestas sin preguntas.

34. En primer lugar, cabe interrogarse sobre la posibilidad de acudir ante tribunales de un Estado miembro -por ejemplo, Alemania, en cuyo Derecho no existe la separación judicial-, e instar, precisamente, dicha separación judicial porque así está contemplado por la Ley que rige dicha separación. Puede ser el caso, supóngase, de dos cónyuges españoles que residen habitualmente en Berlín y Madrid y que presentan su demanda de separación judicial ante tribunales de Berlín. La Ley que rige tal separación es la Ley española (art. 8.c) RR-III).

Pues bien, si dos cónyuges solicitan una separación judicial ante los tribunales de un Estado cuyo Derecho material no regula la separación judicial, el resultado es claro. El tribunal competente debe aplicar la norma de conflicto contenida en el Reglamento roma III, la Ley estatal correspondiente, y debe pronunciarse sobre la separación judicial. Es irrelevante que el Derecho Civil del Estado miembro del que depende el tribunal competente no contemple la separación judicial. Y es irrelevante, también, que el Derecho Procesal de dicho Estado miembro no disponga de un cauce procedimental al respeto. 
En todo caso, el tribunal competente tiene que aplicar la Ley designada por el reglamento y debe pronunciarse sobre la demanda de separación judicial. Sólo de ese modo se garantiza que el resultado es el mismo con independencia del tribunal al que se acuda dentro los Estados miembros de la UE que participan en este reglamento. Si carece de un procedimiento para canalizar la separación judicial deberá activar, por analogía, el procedimiento más similar del que disponga en su normativa procesal o bien activar otros mecanismos procedimentales para aplicar el Derecho extranjero que regula el fondo del asunto y para decidir si procede acordar la separación judicial.

35. En segundo lugar, cabe preguntarse qué sucede si dos cónyuges solicitan una separación judicial ante los tribunales de un Estado miembro y la Ley reguladora de la separación judicial no contempla dicha institución, sino sólo el divorcio. Póngase el caso siguiente: dos alemanes solicitan la separación judicial ante un tribunal español. El marido reside habitualmente en Viena y la esposa reside habitualmente en Madrid. Pues bien, el tribunal competente debe aplicar la norma de conflicto contenida en el Reglamento Roma III así como la Ley estatal correspondiente y debe pronunciarse sobre la separación judicial. La Ley aplicable, al caso hipotético propuesto, es la Ley alemana (art. 8.c) RR-III: Ley nacional común al tiempo de la demanda). Como es lógico, el juez español deberá desestimar la demanda de separación judicial por la sencilla razón de que ésta no se contempla en la Lex Causae, que es la Ley alemana. Fallará, de ese modo, igual que lo haría un juez alemán. Podrá invitar, en su caso, a los cónyuges a presentar una demanda de divorcio con arreglo a la Lex Causae, la Ley alemana. Es totalmente indiferente, a estos efectos, que el Derecho del Estado miembro cuyos tribunales conocen del asunto sí que regule y contemple la separación judicial. La Lex Causae manda.

\section{Las enseñanzas del Tribunal de Justicia de la Unión Europea.}

36. Las enseñanzas del TJUE son claras y representan una fascinante profesión de fe en el Derecho internacional privado europeo. Éste constituye una piedra angular de la construcción jurídica europea y así lo indica el TJUE.

37. En primer lugar, el TJUE deja claro que la seguridad jurídica y la estabilidad de la Ley aplicable al divorcio, son objetivos fundamentales del Reglamento Roma III. La interpretación de este Reglamento y de sus normas debe apuntar a ese objetivo, como sucede en todos los Reglamentos Roma" (= reglamentos que determinan la Ley aplicable a una situación privada internacional). Es un objetivo que debe ser respetado. Una interpretación del reglamento que pudiera traicionar este objetivo debe rechazarse. En suma, resulta primordial que la Ley aplicable al divorcio sea la misma en todos los Estados miembros que participan en el Reglamento Roma III. Es para eso para lo que fueron creados los Reglamentos Roma, para evitar el Forum Shopping mediante normas de conflicto uniformes únicas para toda la UE. Pues bien, para lograr dicha finalidad, las excepciones a la aplicación de las normas de conflicto recogidas en el Reglamento Roma IIII deben interpretarse siempre de manera restrictiva. De esa forma, la Ley aplicable al divorcio será siempre la señalada por las normas de conflicto del Reglamento Roma III. Sólo en casos muy puntuales, totalmente extraordinarios, deben activarse las excepciones a la aplicación de las normas de conflicto del Reglamento Roma III ${ }^{32}$.

La existencia de foros alternativos para pronunciar el divorcio, tal y como establece el art. $3 \mathrm{RB}$ II-bis, está en el origen de las controversias suscitadas en este caso y en tantos otros. Los cónyuges pueden acudir a distintos tribunales de los Estados miembros de la UE para solicitar el divorcio (art. 3 RB II-bis). Por ejemplo, pueden presentar la demanda ante los tribunales de la residencia habitual común o ante los tribunales del Estado miembro cuya nacionalidad ostentan ambos. Y están en su derecho de acudir a unos u otros tribunales aunque ello genere, que la genera, una veloz carrera a los tribunales, y aunque ello provoque, que las provoca, conductas estratégicas y oportunistas de los cónyuges y final-

${ }^{32}$ STJUE 16 julio 2020, C-249/19, JE vs. KF, FD 32-33. 
mente, aunque ello incremente la litigiosidad, como apunta A. Bonomi ${ }^{33}$. Ahora bien, la diversidad de tribunales alternativamente competentes no debe comportar un "cambio en la Ley aplicable" que dependa de cuál sea el tribunal competente. En un espacio europeo de justicia, todos los tribunales aplican la misma Ley estatal a los casos derivados de situaciones privadas internacionales. Así, en los supuestos transfronterizos de divorcio, y a falta de acuerdo entre los cónyuges, el divorcio se rige por la Ley de la residencia habitual común de los mismos en el momento de presentación de la demanda (art. 8.1 RRIII). La Ley aplicable al divorcio no debe cambiar por el hecho de accionar ante unos u otros tribunales. De ese modo, se evita el Forum Shopping y la carrera a los tribunales. Se impide la especulación sobre la Ley aplicable al divorcio, esto es, las conductas estratégicas de los cónyuges para alterar la Ley aplicable al divorcio. Los cónyuges pueden cambiar de tribunal competente y a acudir al tribunal que más cómo les resulte, pero la Ley aplicable no cambiará.

38. En segundo lugar, el TJUE deja claro que la norma de conflicto es una norma elegante. Su esquema racional es, en realidad, muy sencillo. El divorcio se debe regir por la Ley del Estado cuya aplicación es más previsible para los cónyuges implicados. Es ésa la Ley que les comportará costes menores a ambos litigantes en la solución del litigio. Si los cónyuges han elegido la ley aplicable a su divorcio, dicha ley se aplicará, pues la autonomía de la voluntad conflictual es la conexión primera y principal acogida por el Reglamento Roma III, señala la doctrina ${ }^{34}$. En tal caso, como observa H. RösLER, el contenido de dicha Ley es irrelevante en este momento del razonamiento conflictual ${ }^{35}$. Si los cónyuges no la han elegido, entonces el divorcio se rige por la ley del país donde ambos tenían su residencia habitual en el momento de presentación de la demanda de divorcio. La norma de conflicto protege, como hace notar J. CARRASCOSA GonZÁlez, los intereses privados, los intereses de los concretos cónyuges que están implicados en un proceso de divorcio específico ${ }^{36}$. Una vez detectada y precisada la Ley aplicable a un concreto supuesto de divorcio, los tribunales del Estado miembro que conocen del asunto deben aplicar dicha Ley. No se deben admitir, bajo ningún concepto, excusas no justificadas, y mucho menos excusas basadas en el Derecho nacional y todavía menos, fundadas en aspectos de procedimiento. De este modo, si la Ley aplicable al divorcio exige una previa declaración de separación judicial, el tribunal que conoce del divorcio debe acreditar que tal separación judicial se ha producido. Con ello respeta el tenor del Derecho aplicable al fondo del divorcio. Así, aunque el Derecho de un Estado miembro (Rumanía) no disponga en sus normas procesales de un concreto procedimiento de separación judicial, los tribunales de dicho Estado deben entrar en el fondo y decidir si se cumplen los requisitos que el Derecho italiano exige para afirmar que existe una separación judicial. Si las respuesta es afirmativa, entonces podrán pronunciar una sentencia de divorcio.

39. En tercer lugar, de una manera implícita pero no por ello menos firme, el TJUE señala que en principio, todas las Leyes que regulan el divorcio son justas. Salvo infracción del orden público internacional del foro, supuesto excepcional, no es adecuado entrar en una guerra dialéctica sobre la supuesta injusticia del Derecho italiano o irlandés porque son Derechos que regulan un divorcio lento o

${ }^{33}$ A. BonOMI, "La compétence internationale en matière de divorce. Quelques suggestions pour une (improbable) révision du règlement Bruxelles IIbis, RCDIP, 2017-4, pp. 511-534.

${ }^{34}$ M. Ahmed, "The nature and enforcement of choice of law agreements", Journal of Private international Law, 2018, pp. 500-531; L. Álvarez de Toledo Quintana, "El pacto de elección de lex separationis y lex divorcii en el Reglamento 1259/2010”, Diario La Ley, núm. 7613, 18 abril 2011, pp. 1-7; G. BIAGIONI, "Tecniche Internazionaleprivatistiche fondate sulla volontà delle parti nel Diritto dell'Unione Europea”, CDT, 2010, vol.2, núm. 2, pp. 16 ss.; M. BRosch, Rechtswahl und Gerichtsstandsvereinbarung im internationalen Familien- und Erbrecht der EU, Tübingen, Mohr Siebeck, 2019; I. QUEIROLO / L. CARPANETO, «Considerazioni critiche sull'estensione dell'autonomia privata a separazione e divorzio nel regolamento Roma III», RDIPP, 2012, pp. 59-86.

${ }^{35}$ H. RöSLER, "Rechtswahlfreiheit im Internationalen Scheidungsrecht der Rom III-Verordnung", RabelsZ, vol. 78, n. 1, enero 2014 , pp. 155-192.

${ }^{36}$ J. Carrascosa GonzÁlez, "La Ley aplicable a la separación judicial y al divorcio en defecto de elección de ley por los cónyuges. Análisis del artículo 8 del Reglamento 1259/2010 de 20 diciembre 2010", Cuadernos de Derecho Transnacional (CDT), 2012, núm. 1, pp. 52-85. 
complejo. Todos los Derechos son justos para la sociedad que regulan. Esta toma de posición del TJUE es emocionante. En vez de estar constantemente juzgándose los unos a los otros mediante un orden público agresivo y desmesurado, los Estados deben confiar en que la regulación del divorcio contenida en una Ley extranjera es, en principio, una expresión de la Justicia y deben aplicar dicha Ley ${ }^{37}$. Indica el TJUE que los tribunales de los Estados miembros que participan en el reglamento Roma III deben evitar una visión o "apreciación subjetiva" de las leyes extranjeras que regulan el divorcio. No deben juzgar las leyes extranjeras con sus lentes jurídicas nacionales. Se trata de una idea savignyana, naturalmente, anclada en la "comunidad jurídica de naciones", la famosa völkerrechtliche Gemeinschaft, una de las ideas persistentes del Derecho internacional privado, escribe J. CARRASCosa GonZÁlez ${ }^{38}$. Acabar con los prejuicios nacionalistas es uno de los objetivos más hermosos del Derecho internacional privado.

40. En definitiva, el Reglamento Roma III se muestra como un micro sistema conflictual técnicamente muy cuidado y construido sobre principios conflictuales sólidos, precisa M. FALLON ${ }^{39}$. Es, por ello, un reglamento elegante: le mot juste. Con un reducido número de normas de conflicto que proporcionan soluciones sencillas y que responden a una lógica conflictual clara, el reglamento contribuye de manera evidente y firme a alcanzar resultados positivos para un espacio europeo de justicia.

\footnotetext{
${ }^{37}$ STJUE 16 julio 2020, C-249/19, JE vs. KF, FD 32.

${ }^{38}$ J. Carrascosa González, Dogmática jurídica y Derecho internacional privado, Comares, Granada, 2021 (en curso de publicación).

${ }^{39}$ M. FALlon, "Le nouveau droit du divorce international selon le Règlement Rome III: une evolution tranquille", Revue trimestrielle de droit familial, 2012, pp. 291-318.
} 